\title{
Artificial Photosynthesis
}

\author{
Gion Calzaferri
}

Published online: 4 December 2009

(C) Springer Science+Business Media, LLC 2009

\begin{abstract}
One-dimensional channel materials, such as zeolites and mesoporous silicas, are very attractive hosts for the preparation and investigation of hierarchically organized structures, presenting a successive ordering from the molecular up to macroscopic scale. The focus of this article is on artificial photonic antenna systems and on photocatalytically active layers that have been built by incorporating organic dyes, complexes, metal cations and clusters into 1-D nanochannel materials. We show that zeolite $\mathrm{L}$ as a host material allows for the design and preparation of a large variety of highly organized hostguest systems. The combination of a tuneable host morphology and the possibility of obtaining highly organized molecular patterns of guests leads to a variety of potential optical and photoelectronic applications. Strongly absorbing systems exhibiting efficient FRET along the c-axis of the zeolite crystals are accessible by sequential inclusion of multiple types of dyes. These new light-harvesting materials offer unique possibilities as building blocks for solarenergy conversion devices. A complementary approach consists in integrating photochemically active substances into zeolite monolayers coated on an electrode and taking advantage of intrazeolite processes for designing a reversible electrode for photocatalytic water oxidation. The photoelectrochemical water splitting capability of systems based on $\mathrm{Ag}^{+} / \mathrm{AgCl} / \mathrm{Ag}_{\mathrm{n}}$-zeolite photoanodes are discussed.
\end{abstract}

G. Calzaferri $(\bowtie)$

Department of Chemistry and Biochemistry, University of Bern,

Freiestrasse 3, 3012 Bern, Switzerland

e-mail: gion.calzaferri@iac.unibe.ch

URL: http://www.dcb-server.unibe.ch/groups/calzaferri
Keywords Hybrid materials - Zeolites - FRET · Luminescence concentrator - Water splitting . Silver chloride $\cdot$ Silver cluster

\section{Introduction}

Structurally organized and functionally integrated artificial systems that are capable of elaborating the energy and information input of photons to perform functions, like processing and storing information, sensing microscopic environment on a nanoscale level or transforming and storing solar energy, are fascinating topics of modern photochemistry [1-3]. 1-D channel materials, such as zeolites and mesoporous silicas, are very attractive hosts for the preparation and investigation of hierarchically organized structures, presenting a successive ordering from the molecular up to macroscopic scale; thus highlighting the relationship between molecular arrangements and macroscopic properties [3-8]. The maintenance of life on earth, food, oxygen, and fossil fuels depend on the conversion of solar energy into chemical energy by biological photosynthesis carried out by green plants. In this process sunlight, water and carbon dioxide, abundant raw materials, are converted to reduced organic species, that serve as food and fuel, and to oxygen [9]. The overall thermodynamic efficiency of the natural photosynthesis for the production of fuel is low and depends very much on optimal soil, temperature and humidity conditions. The natural process has many other important tasks to fulfill, however, than just conversion of solar light into a chemical fuel, as illustrated in Fig. 1 on the left side. A longstanding challenge has therefore been the development of a practical artificial photosynthetic system that is able to carry out the energy conversion process not by duplicating 
Fig. 1 Quantum solar energy conversion. Left illustration of the principle and the beauty of natural photosynthesis. Right principle of an artificial quantum solar energy conversion system
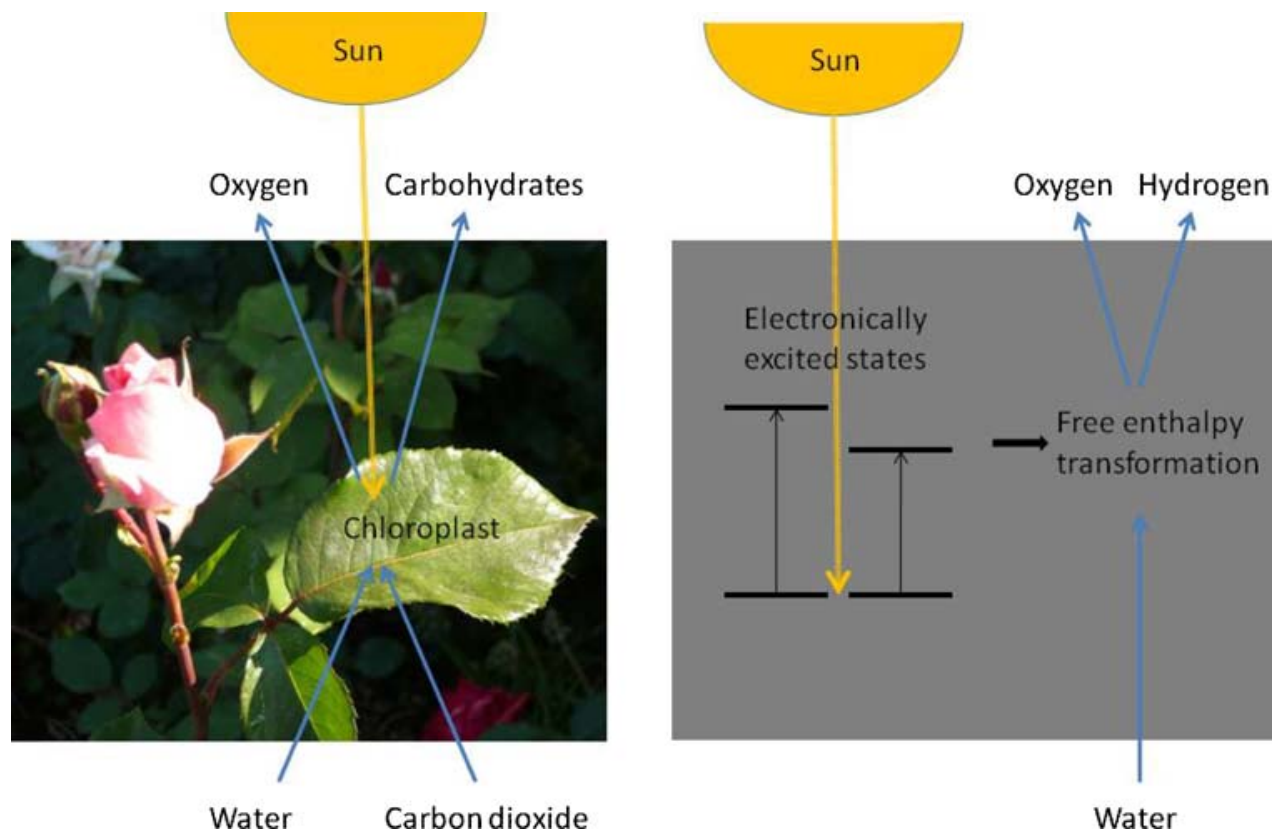

Water the self-organization and reproduction of the biological system nor the aesthetic beauty of plants and trees, but rather by being able to use sunlight to drive a reaction of abundant materials to produce a fuel; right side of Fig. 1 [1-3], [9-14].

The focus of this article is on artificial photonic antenna systems and on photocatalytically active layers that have been built by incorporating organic dyes, metal complexes, metal cations and clusters into 1-D nanochannel materials. Before going into this it is useful to recall the simplified but yet useful overview of the interaction of light with matter presented in Fig. 2. Light that has been absorbed by matter is in a first step stored for a very short time as kinetic energy of electrons which can either be transformed into kinetic energy of the nuclei and released as heat or emitted as light of somewhat longer wavelength. It can also create an electron-hole pair which can e.g., be used to drive a photocurrent or it can act as reagent for alteration of mater in a photochemical reaction. Thermal solar energy conversion has many important applications which will, however, not be addressed in this article. Quantum solar energy conversion means direct utilization of the electronic excitation energy by creating photovoltage and photocurrent or by transforming the electronic excitation energy in a photochemical or photocatalytic reaction into free enthalpy stored as a chemical fuel [1-3], [9-15].

\section{Artificial Antenna Systems}

Green plants have developed very sophisticated tools for trapping light and transporting electronic excitation energy

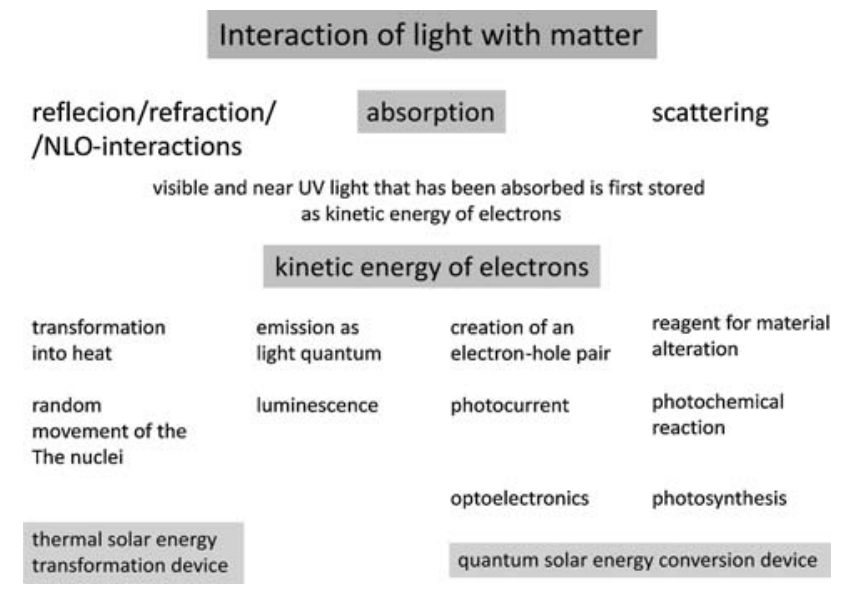

Fig. 2 Interaction of light with matter and transformation of solar energy

in their antenna system. We understand the detailed structure of the antenna system of purple bacteria. It consists of regular arrangements of chlorophyll molecules held at fixed positions by means of proteins [1, 2], [15]. Light absorbed by any of these chromophores is transported to the reaction center, providing the energy necessary for chemical processes to be initiated. A green leaf consists of millions of such well organized antenna devices.

The understanding of the basic principles that govern the transport of electronic excitation energy is very advanced. It goes back to the pioneering work of Theodor Förster [16]. A chlorophyll molecule consists essentially of a positively charged backbone with some delocalized electrons. The energy of an absorbed photon is transformed into kinetic energy of one of these delocalized electrons. 
This fast moving electron causes an oscillating electromagnetic field that can interact with a neighboring acceptor molecule $A$, if the latter bears states that are in resonance with the excited state of the donor $D^{*}$. Thus the excitation energy can be transferred from one molecule to an other. The radiationless electronic excitation energy transfer (EnT) is due to the very weak near field interaction between excited configurations of the initial state $\left(D^{*} \ldots A_{i}\right)$ and of the final state $\left(D \ldots A_{i}^{*}\right)$. The Förster resonance energy transfer (FRET) mechanism involves no orbital overlap between the donor and acceptor molecules, and thus no electron transfer occurs.

$\left(D * \cdots A_{i}\right) \stackrel{k_{\text {EnT } T}(i)}{\longrightarrow}\left(D \cdots A_{i} *\right)$

In such a system the "optical electrons" associated with individual chromophoric units preserve essentially their individual characteristic. The donor $D$ and the acceptor $A_{i}$ can be the same kind of molecules or they can be different. Förster observed that the rate constant $k_{E n T}$ for the transfer from one electronic configuration to the other can be expressed as a product of three terms:

$k_{E n T} \propto G \cdot D A \cdot S$

The geometrical term $G$ describes the dependence of the rate constant on the distance and angle between the electronic transition dipole moments (ETDM) of the donor and the acceptor. DA specifies the chromophores involved, by taking into account the resonance condition as well as the photophysical properties of the donor, while the factor $S$ takes into account the environment.

Our design of a model mimicking the key functionality of the green plants antenna system was inspired by the experience we had with different zeolite materials $[17,18]$. The properties of molecules, complexes and clusters inside cavities and channels of zeolites-apart from the field of catalysis-have been investigated for many years [19-30].
A 1-D channel system has the advantage of being the simplest possible choice, as is illustrated in Fig. 3. The donor molecules are represented in green and the acceptors in red. The donor, being excited by photon absorption, transfers its electronic excitation to an unexcited neighbor. After series of such steps, the electronic excitation reaches a luminescent trap (acceptor molecule) and is then released as luminescence. The acceptors are thought to mimic the "entrance of the reaction center" of the natural antenna. The dimensions given in Fig. 3 correspond to the pore opening and the center to center distance between two neighboring channels in zeolite L. According to Förster theory, the largest EnT rate constant is observed if the ETDM are oriented parallel to the channel axis. Electronic excitation energy transport can be extremely fast in such systems because of the low dimensionality [4].

Different materials bearing 1-D channels can be envisaged for realizing the situation sketched in Fig. 3. We found that zeolite L is an excellent host for the supramolecular organization of organic dyes. The synthesis of zeolite L crystals of different morphologies in the size range of $30 \mathrm{~nm}$ up to about $10,000 \mathrm{~nm}$ is well established [30-39]. We therefore focus on systems based on zeolite L as a host. The reasoning is, however, also valid for other host materials with similar properties. The structure and morphology of zeolite $\mathrm{L}$ is illustrated in Fig. 4. The primary building unit of the framework consists of $\mathrm{TO}_{4}$ tetrahedrons where $\mathrm{T}$ represents either $\mathrm{Al}$ or $\mathrm{Si}$. The channel system exhibits hexagonal symmetry. The molar composition of zeolite $\mathrm{L}$ is $\left(\mathrm{M}^{+}\right)_{9}\left[\left(\mathrm{AlO}_{2}\right)_{9}\left(\mathrm{SiO}_{2}\right)_{27}\right] \times \mathrm{nH}_{2} \mathrm{O}$, where $\mathrm{M}^{+}$are monovalent cations, compensating the negative charge resulting from the $\left(\mathrm{AlO}_{2}\right)$-unit. $n$ is equal to 21 in fully hydrated materials, and to 16 for crystals equilibrated at about $22 \%$ relative humidity [38], [40]. It is useful to imagine zeolite $\mathrm{L}$ as consisting of a bunch of strictly parallel channels as shown in Figs. 3 and 4 d. The channels have a smallest free diameter of about $0.71 \mathrm{~nm}$,
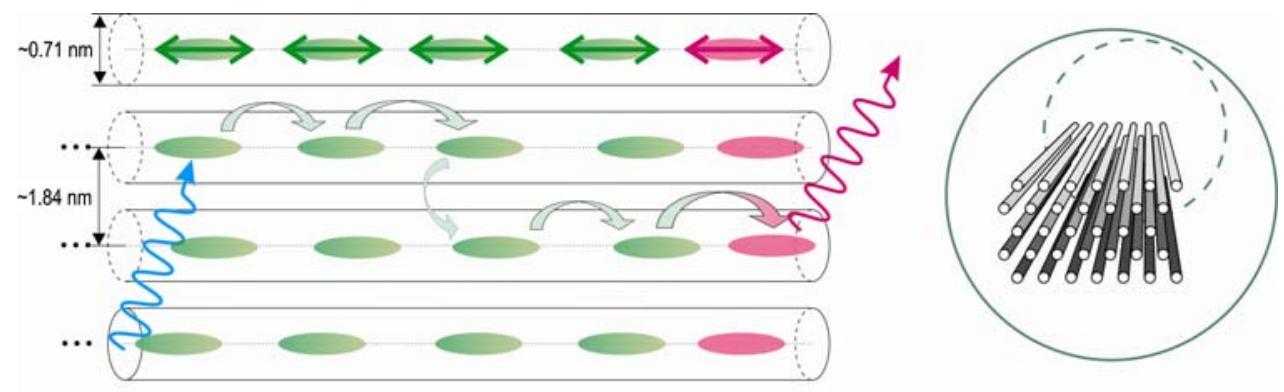

Fig. 3 Schematic overview of an artificial photonic antenna. Left the chromophores are embedded in the channels of the host. The green dyes act as donor molecules that absorb the incoming light and transport the electronic excitation energy via FRET to the red acceptors shown at the ends of the channels on the right. The process can be analyzed by measuring the emission of the red acceptors and comparing it with that of the donors. The double arrows indicate the orientation of the ETDM. Right Top view of a bunch of such strictly parallel channels 

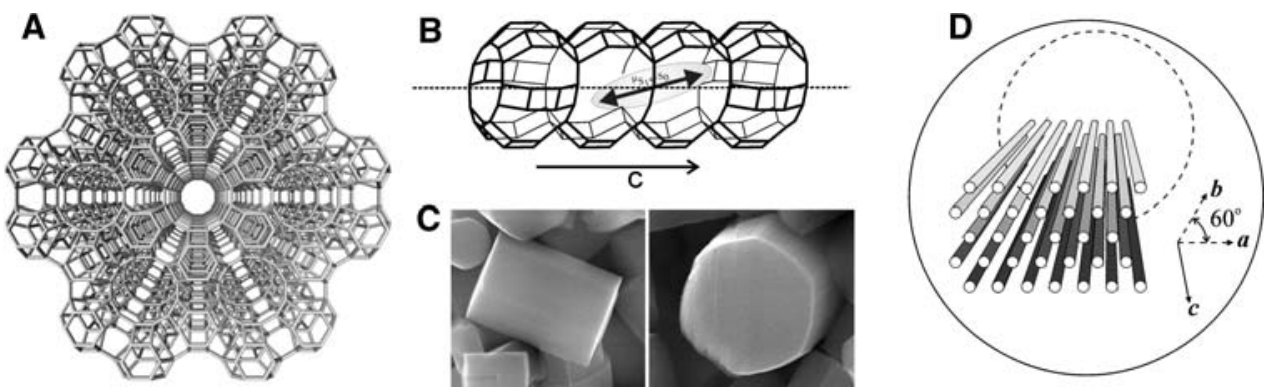

Fig. 4 Zeolite L. a Top view of the framework of zeolite L, illustrating the hexagonal structure. It shows a channel surrounded by six neighboring channels. b Side view of a channel that consist of $0.75 \mathrm{~nm}$ long unit cells with a Van der Waals opening of $0.71 \mathrm{~nm}$ at the smallest and $1.26 \mathrm{~nm}$ at the widest place. The double arrow

the largest diameter inside is $1.26 \mathrm{~nm}$. The distance between the centers of two neighboring channels is $1.84 \mathrm{~nm}$. Each zeolite L crystal consists of a large number of channels $\left(n_{c h}\right)$ which can be estimated as follows: $[3,4]$

$n_{c h}=0.267\left(d_{Z}\right)^{2}$

where $d_{Z}$ is the diameter of the crystal in $\mathrm{nm}$. For example, a crystal with a diameter of $600 \mathrm{~nm}$ features nearly 100,000 strictly parallel channels. The ratio of void space available in the channels with respect to the total volume of a crystal is about 0.26 . An important consequence is that zeolite $\mathrm{L}$ allows, through geometrical constraints, the realization of extremely high concentrations of well oriented molecules that behave essentially as monomers. A $30 \mathrm{~nm}$ by $30 \mathrm{~nm}$ crystal can accept up to nearly 5,000 dye molecules that occupy 2 unit cells; while a $60 \mathrm{~nm}$ by $60 \mathrm{~nm}$ crystal can host nearly 40,000. Many different molecules, complexes and clusters have been inserted into the channels of zeolite L.

We already stated that the focus is on situations where molecules behave in the states of interest as individuals, which means that the "optical electrons" associated with the chromophoric units preserve essentially their individual characteristics. They can, however, communicate with each other. We are interested in molecules that are so large that they can neither pass each other inside of the channels nor sit on top of each other, as illustrated in Fig. 5. The geometrical constraints imposed by the host determine the orientation of the dye molecules inside the channels and hence the orientation of the ETDM. Exciton splitting becomes important at sufficiently short distances between the ETDM of neighboring chromophores [4], [41-44].

From the whole volume of the zeolite only a part, namely the channels, is available for the guest species. It is therefore convenient to introduce a parameter bearing the information on dye concentration that is based on purely geometrical (space-filling) properties of the host, i.e., indicates the ETDM of an inserted molecule. c SEM image of zeolite $\mathrm{L}$ crystals with a diameter of about $600 \mathrm{~nm}$. d Schematic view of the channels. The center to center distance between two channels is $1.84 \mathrm{~nm}$
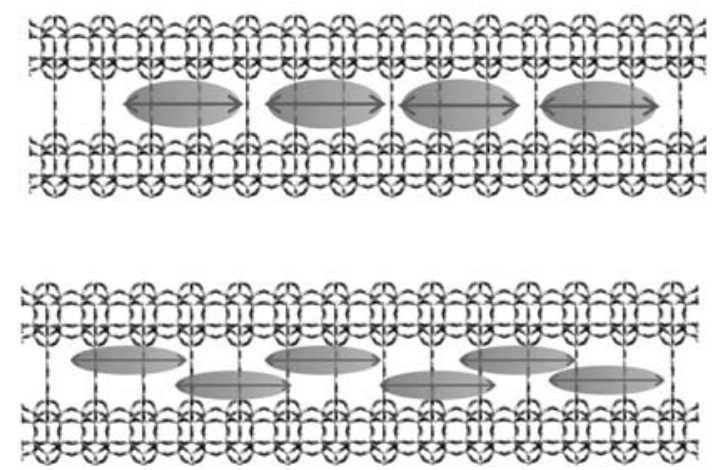

Fig. 5 Packing of dyes in the channel, explained by means of a simplified view of different orientations and two arrangements of molecules in a channel. The orientation of the ETDM is indicated by a double-arrow. Top the molecule on the left is small enough to fit into one unit cell and its shape is such that the ETDM is oriented nearly perpendicular to the channel axis. Then we see a molecule that occupies two unit cells and is oriented at an angle of about $45^{\circ}$. The next molecule is so large that it can only align parallel to the channel. On the right we illustrate a situation where two molecules come so close that their orientation and their optical properties are influenced by the packing. Middle orientation of large molecules which align parallel to the channel axis because of their size and their shape. Bottom stacking of molecules of appropriate size and shape, leading to excitonic states [4], [40-42]

showing to what extent the zeolite channels are filled with dye molecules. The loading, or occupation probability, $p$ of a dye-zeolite L material is defined in Eq. 4.

$p=\frac{\text { number of occupied sites }}{\text { total amount of sites }}$

The site $n_{s}$ represents the number of unit cells occupied by one dye molecule. It can, for example, be equal to 1,2 


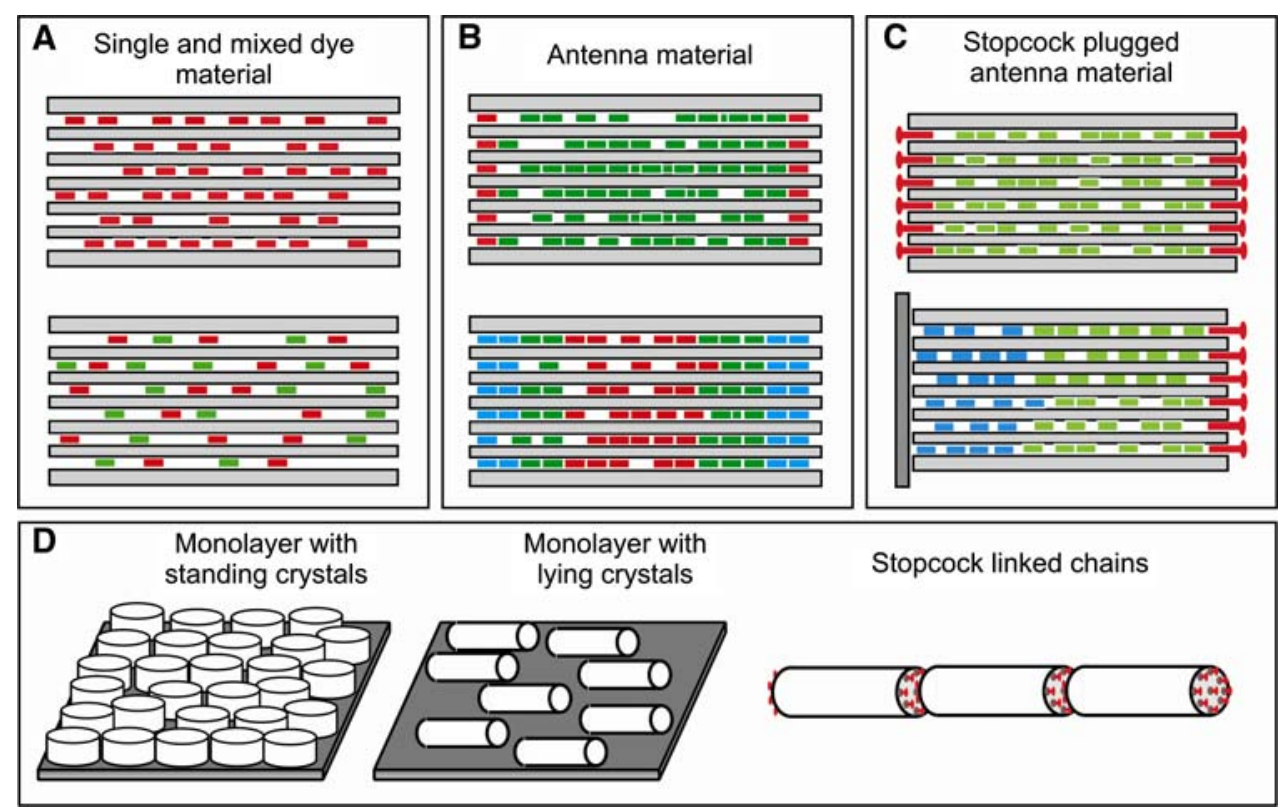

Fig. 6 Schematic representations of supramolecularly organized dyezeolite L composites. a Single and mixed dye materials are obtained by either loading zeolite crystals with one kind of dye (top) or by simultaneous insertion of different dye molecules (bottom). b Antenna materials, prepared by sequential insertion of different dyes. c Stopcock-plugged antenna material, obtained by modifying either

or larger. $n_{s}$ must not necessarily be an integer number. The loading ranges from 0 for an empty zeolite to 1 for a fully loaded one. The dye concentration of a dye-zeolite material $c(p)$ in units of $\mathrm{mol} / \mathrm{L}$ can be expressed as a function of the loading as follows:

$c(p)=0.752 \frac{p}{n_{s}}\left(\frac{m o l}{L}\right)$.

Försters theory leads to a simple expression for the EnT rate constant that contains only experimentally accessible parameters [16]. This is of great value. The same is true for Davydows theory to describe exciton coupling in such systems [43]. Both have been found to be very useful for designing and understanding organized systems based on nanochannel materials [3, 4], [6], [40-42], [44-46]. The FRET process can be extended from the inside of a crystals to its environment (or vice versa) by means of so called stopcock molecules [4], [45, 46]. Such stopcock molecules consist of a head group that is too large to pass the pore opening and a tail that fits into the channel. These chromophores are therefore located at the zeolites basal surfaces and can promote the communication between the dyes inside the crystal and the outside world.

It has been shown that zeolite $\mathrm{L}$ as a host material allows for the design and preparation of a large variety of highly organized host-guest systems. Relevant types are illustrated in Fig. 6. Important steps in the development of these composite materials were the sequential filling with bidirectional (top) or mono directional (bottom) antenna materials with specific closure molecules, called stopcocks. d Organization of zeolite L crystals. Oriented monolayers of either standing or lying zeolite L crystals on a substrate and chains of crystals linked by the interaction between the stopcocks located at the channel entrances [4], [6], [42]

different dyes, the invention of the stopcock principle, the discovery of quasi 1-D energy transfer, the preparation of unidirectional energy transfer material and finding ways to create hybrid materials fully transparent in the visible range. The latter is important for spectroscopic investigations, since zeolite crystals exhibit considerable light scattering due to their size and refractive index. For a more detailed discussion of this we refer to refs. [4] and [42]. Zeolite L is the only currently available microporous material allowing the realization of the full range of organizational patterns presented here. It is, however, interesting and worthwhile to investigate to what extent other zeolite based materials [47] but also materials based on a mesoporeous hoste can be used for extending the organizational patterns already realize based on zeolite L [6].

The range of possibilities for filling the 1-D channels with different suitable guests has been shown to be much larger than one might expect at a first glance [4], [6], [42]. Geometrical constraints imposed by the host structure lead to supramolecular organization of the guests in the channels, as illustrated in Fig. 6. The supramolecular organization of dyes inside the zeolite channels is what we call the first stage of organization. It allows light harvesting within the volume of a dye-loaded zeolite L crystal and also radiationless energy transport to either the cylinder ends or to the centre. 1-D FRET transport has been observed in these guest-host materials as illustrated in Fig. $7 \mathrm{a}$. 


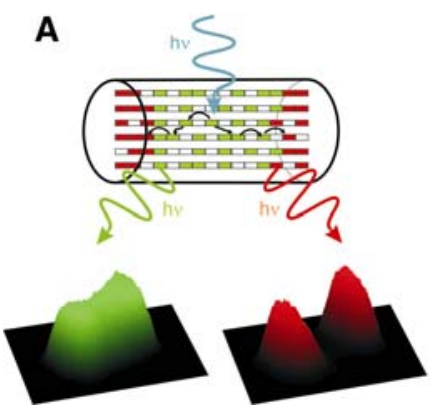

Fig. 7 Dye-zeolite L antenna systems. a Fluorescence behavior of a donor,acceptor-zeolite L antenna. Top scheme of an antenna crystal and processes taking place upon excitation of a donor molecule (green) absorption of incident light, energy migration from an excited donor molecule to a neighboring unexcited one and trapping by an acceptor (red), fluorescence of both donor and acceptor. Lower confocal microscopy images of an antenna crystal upon selective
B

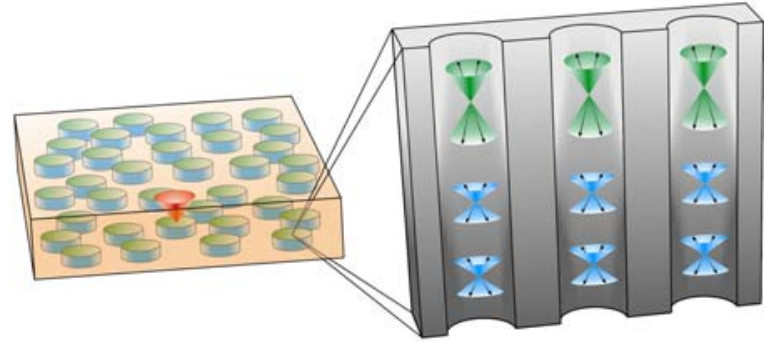

excitation of the donor and observation trough an appropriate filter (left) and upon selective excitation of the acceptor (right). b The alignment of dye molecules in the channels of zeolite L can be extended to the macroscopic scale by preparing monolayers of crystals with defined morphology. Systems including multiple types of dye monomers form the basis for the design of novel device architectures in the field of optical and photoelectronic applications
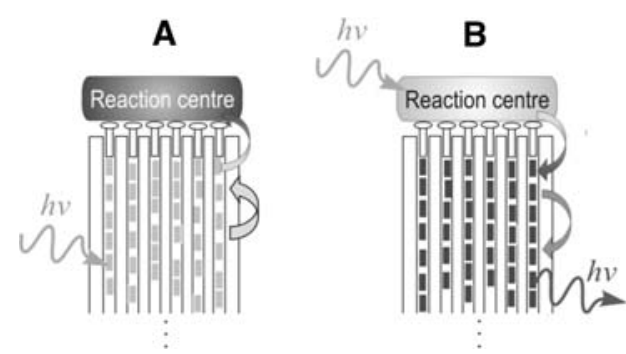

Fig. 8 Communication of guests with an external reaction center via FRET. Non fluorescent stopcock molecules can be used if they act as insulating or protecting chemical linkers between the dyes inside the channels and the chromophores located at the reaction center; (a) and (b). We illustrate in $\mathbf{c}$ and $\mathbf{d}$ that a thin insulating part between the luminescent stopcock and the reaction center is usually desirable if

The second stage of organization is represented by the coupling of an external acceptor or donor stopcock fluorophore at the ends of the zeolite L channels, which can then trap or inject electronic excitation energy [4], [45, 46], [48, 49]. The third stage of organization is obtained by interfacing the material to an external device via a stopcock intermediate; see Fig. 8 [4]. A possibility of achieving a higher level of organization is the controlled assembly of the zeolite crystals into oriented structures and the preparation of monodirectional materials [4], [6, 7], [47], [50-52]. The usually strong light scattering of zeolite L can be suppressed by refractive index matching and avoidance of microphase separation in hybrid polymer/dye-zeolite $\mathrm{L}$ materials [53].

\subsection{Applications}

The combination of a tuneable host morphology, of highly organized molecular patterns of guests and the possibility to organizing the nano- and micro-crystals leads to a large
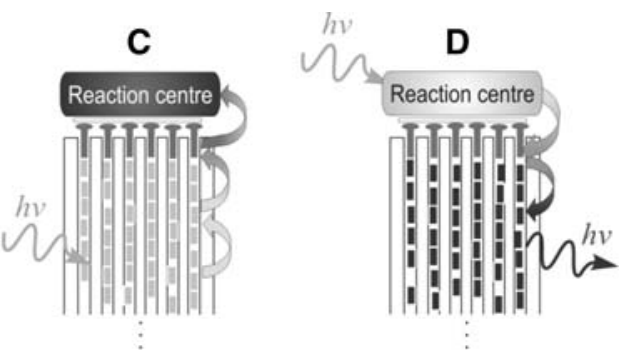

the stopcocks are luminescent molecules in order to avoid direct contact which might lead to electron transfer or other undesirable reactions. The insulating part can e.g., be covalently bound to either the stopcock or the reaction center. The distance between donors and acceptors should be shorter than the Förster radius if efficient FRET is desired [4]

variety of potential optical and photoelectronic applications of dye-zeolite L materials. Strongly absorbing systems exhibiting efficient FRET along the c-axis of the zeolite crystals are accessible by inclusion of multiple types of dyes. They form a basis for novel light-harvesting devices. The FRET processes can be fine-tuned by an appropriate choice of dye molecules, whereas the ordering of the dyes can be extended to the macroscopic level by clever arrangement of the host. The robust zeolite framework can further be selectively functionalized at the external crystal surfaces and at the pore entrances. This versatility can be exploited to establish communication pathways by means of FRET.

These new materials offer unique possibilities as building blocks for solar-energy conversion devices. A new type of dye-sensitized solar cell works by first absorbing light over a broad spectral range in the zeolite-antenna material; see Fig. 9a-c. The excitation energy migrates radiationless among the inserted dyes toward the stopcocks. From there, FRET to the semiconductor takes place across a very thin 
A

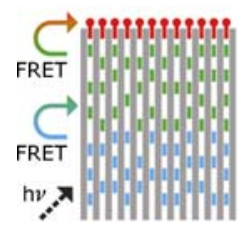

B

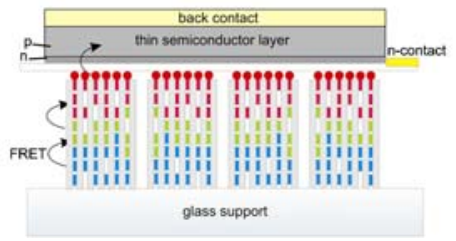

Fig. 9 New building blocks for solar-energy-conversion devices. a Schematic overview of the host material, consisting of nanochannels containing two types of dye molecules (blue and green) and stopcocks (red). Light absorbed by the blue and also by the green molecules travels to the stopcock heads radiationless, via FRET. b and c Principle of dye-sensitized solar cells [54]. Arranging crystals of $50 \mathrm{~nm}$ to a few $100 \mathrm{~nm}$ length with their channel axes perpendicular to the surface of a semiconductor allows transport of the excitation energy toward the zeolite-semiconductor interface by FRET. The

insulating layer. The injected energy can now be used to drive the charge-separation process in the active medium [54]. The idea of using luminescent solar concentrators LSC has been know since about 50 years [55-58]. An LSC is a transparent plate containing luminescent chromophores. Light enters the face of the plate, is absorbed and subsequently re-emitted. The luminescent light is trapped by total internal reflection and guided to the edges of the plate, where it can be converted to electricity by a solar cell. As the edge area of the plate is much smaller than the face area, the LSC operates as a concentrator of light. A major loss is caused by the overlap between the dye's absorption and emission spectra. Previous efforts to solve this problem have not been successful so far. Recently, however, new materials and techniques have become available to solve the major problems. They have created new interest [59-63]. Our solution to solve the self-absorption problem is to use a well designed dye-zeolite L antenna material [62, 63]. Absorption and emission spectra are separated by employing an absorbing dye present in large amounts, and a monolayer of an emitting dye. The photostability of many dyes is considerably improved by embedding them into the zeolite channels, which protects them because of their confinement; see Fig. 9d [6], [62, 63]. We conclude that new dye-zeolite L based building blocks are now ready to be tested in devices. Their size, morphology, and optical properties will need to be tailored to the specific task envisaged. The remaining problems to be solved require efforts at the interface of chemistry, physics, and engineering.

\section{Photocatalytic and Photoelectrochemical Water Splitting}

A large variety of photoactive materials have been studied in which zeolites host metal cations, metal clusters, metal complexes and also rare earth complexes [64-72].

C
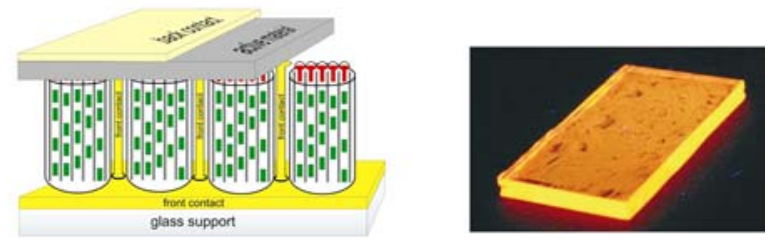

semiconductor layer can be very thin, because the electron-hole (n-p) pairs form near the surface. The transfer of electrons from the antenna to the semiconductor is prevented by introducing a thin insulating layer. Scheme b shows the principle of the operation of thin-layer silicon devices, while scheme c represents that of organic or plastic solar cells. The white area on top of the head is an insulating part directly integrated into the stopcock. The zeolite material is enlarged with respect to the rest of the device. d Small fluorescent concentrator $\left(2 \times 1 \mathrm{~cm}^{2}\right)[62]$

Therefore, a complementary approach to what has been discussed in the last chapter consist in integrating photochemically active substances into zeolite monolayers coated on an electrode and taking advantage of intrazeolite processes for designing a reversible electrode for photocatalytic water oxidation. It has been shown that a thin silver chloride layer deposited on a conducting support photocatalyzes the oxidation of water to $\mathrm{O}_{2}$ in the presence of an excess of silver ions [73]. Silver cations adsorbed at the surface of silver chloride nanocrystals are necessary for the reaction to proceed. Thus, the light absorption can be considered as a charge-transfer excitation from $\mathrm{Cl}^{-}$to adsorbed $\mathrm{Ag}^{+}$. The light sensitivity in the visible part of the spectrum is due to self-sensitization caused by reduced silver species. The overall stoichiometry of the reactions involved in the photooxidation of water to $\mathrm{O}_{2}$ is the following:

$$
\begin{aligned}
& {\left[n \mathrm{Ag}^{+}, m \mathrm{AgCl}\right]} \\
& \quad+\frac{r}{2} \mathrm{H}_{2} \mathrm{O} \stackrel{\text { Light }}{\longrightarrow}\left[(n-r) \mathrm{Ag}^{+}, m \mathrm{AgCl}, r \mathrm{Ag}^{0}\right]+r \mathrm{H}^{+} \\
& \quad+\frac{r}{4} \mathrm{O}_{2} \\
& {\left[(n-r) \mathrm{Ag}^{+}, m \mathrm{AgCl}, r \mathrm{Ag}^{0}\right] \stackrel{\text { polarization }_{\longrightarrow}}{\longrightarrow}\left[n \mathrm{Ag}^{+}, m \mathrm{AgCl}\right]} \\
& \quad+r \mathrm{e}^{-}
\end{aligned}
$$

To test the water splitting capability, $\mathrm{Ag}^{+} / \mathrm{AgCl} / \mathrm{Ag}_{\mathrm{n}}$ photoanodes were combined with an amorphous silicon solar cell. The $\mathrm{AgCl}$ layer was employed in the anodic part of a photoelectrochemical setup consisting of two compartments. A platinum electrode and an amorphous silicon solar cell were used in the cathodic part. Illumination of the $\mathrm{Ag}^{+} /$ $\mathrm{AgCl} / \mathrm{Ag}_{\mathrm{n}}$ photoanode and the amorphous $\mathrm{Si}$ solar cell led to photoelectrochemical water splitting to $\mathrm{O}_{2}$ and $\mathrm{H}_{2}$; see Fig. 10 (left) [74]. In other yet preliminary experiments we prepared zeolite monolayers on conducting surfaces like gold coated glass and gold foil [75]. For the preparation of the monolayers, cubic crystals of zeolite A and disc-shaped 
Fig. 10 Photoelectrochemical experiments with $\mathrm{AgCl} / \mathrm{Ag}^{+}$/ $\mathrm{Ag}_{\mathrm{n}}$ based photanodes under illumination in the range of $350-700 \mathrm{~nm}$ in a flow system where the $\mathrm{O}_{2}$ and $\mathrm{H}_{2}$ were constantly removed; for details see ref [74]. Left $\mathrm{O}_{2}$ and $\mathrm{H}_{2}$ production and anodic photocurrent versus time for an $\mathrm{AgCl}$ layer modified with $\mathrm{Au}$ colloids combined with a Pt cathode and an a-Si:H solar cell for several light and dark cycles. Right the image shows an SEM image of an $\mathrm{AgCl} / \mathrm{Ag}^{+} / \mathrm{Ag}_{\mathrm{n}}$ modified zeolite A monolayer on a gold substrate.

Superimposed is the $\mathrm{O}_{2}$ production observed under illumination [75]
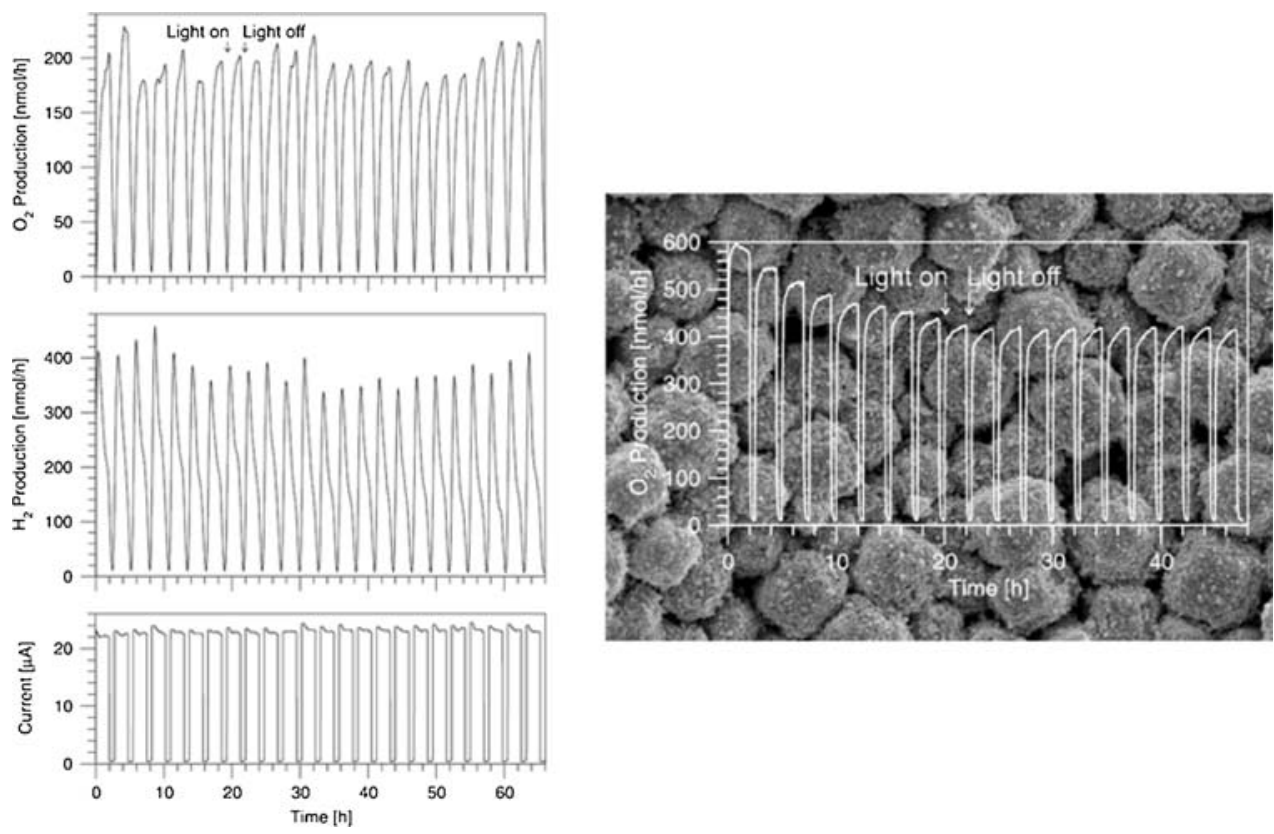

crystals of zeolite L were used. The zeolites were linked to the gold surface by means of a thiolalkoxysilane as molecular linker. The monolayers were then modified with $\mathrm{Ag}^{+}$and $\mathrm{AgCl}$. The so prepared $\mathrm{AgCl} / \mathrm{Ag}^{+} / \mathrm{Ag}_{\mathrm{n}}$-zeolite photo-anodes showed an increased water oxidation capability; see Fig. 3 (right). We have good reasons to assume that utilization of oriented, dense and high quality zeolite L monolayers, consisting of disc shaped crystals with a length of about $100 \mathrm{~nm}$, well attached with their base on a gold electrode, will lead to a considerable improvement of these photoanodes for water oxidation.

In all these photoreactions water is oxidized to oxygen plus protons, and silver cations are reduced to silver upon irradiation according to Eq. 6. Electrochemical reoxidation of the accumulated silver can be performed by anodic polarization of the electrode by means of a potentiostat; Eq. 7. The water oxidation reaction and the reoxidation of the reduced silver species take place simultaneously, making the system catalytic. The electron hole pairs formed upon illumination may recombine, or they may separate and produce silver atoms $\mathrm{Ag}^{0}$ and chlorine radicals $\mathrm{Cl}^{\bullet}$ radicals; Eq. 8. The $\mathrm{Cl}^{\bullet}$ radicals recombine very fast to form $\mathrm{Cl}_{2}$; Eq. 9. The indices $s$ and $i$ in Eqs. 8 and 9 refer to surface and interstitial species.

$[m \mathrm{AgCl}]\left\{\mathrm{Ag}^{+}\right\}_{s} \stackrel{\text { Light }}{\longrightarrow}[(m-1) \mathrm{AgCl}]\left\{\mathrm{Ag}^{+}, \mathrm{Ag}^{0}\right\}_{s, i}+\mathrm{Cl}_{s}^{\bullet}$

$2 \mathrm{Cl}_{s}^{\bullet} \rightarrow \mathrm{Cl}_{2}$

Under the applied conditions $\left(\left[\mathrm{Ag}^{+}\right] \sim 10^{-3} \mathrm{M}\right.$, $\mathrm{pH} \sim 4-6)$, the $\mathrm{Cl}_{2}$ reacts with water to produce hypochloric acid; Eq. 10. At lower $\mathrm{pH}$ and without $\mathrm{Ag}^{+}$ excess in the electrolyte $\mathrm{Cl}_{2}$ can be detected. Silver cations act as a catalyst for the decomposition of $\mathrm{HOCl}$ to molecular oxygen, protons and chloride ions; Eq. 10. The chloride ions are bound by the $\mathrm{Ag}^{+}$to form $\mathrm{AgCl}$; Eq. 12 . These reactions are very fast and it is resonable to assume that they take place at or very near the surface of the electrode.

$$
\begin{aligned}
& \mathrm{Cl}_{2}+\mathrm{H}_{2} \mathrm{O} \rightarrow \mathrm{HOCl}+\mathrm{H}^{+}+\mathrm{Cl}^{-} \\
& 2 \mathrm{HOCl} \stackrel{A g^{+}}{\longrightarrow} \mathrm{O}_{2}+2 \mathrm{H}^{+}+2 \mathrm{Cl}^{-} \\
& {[(m-1) \mathrm{AgCl}]+\mathrm{Ag}^{+}+\mathrm{Cl}^{-} \rightarrow[m \mathrm{mgCl}]}
\end{aligned}
$$

The reduced silver atoms may react according to Eq. 8, forming positively charged or neutral silver clusters. In its first stages, this reaction is related to the fundamental process of latent image formation in silver halides [76].

$\mathrm{Ag}^{0}+\mathrm{Ag}_{r}^{\mathrm{q}+} \rightarrow \mathrm{Ag}_{(r+1)}^{\mathrm{q}+} \quad(r \geq 1 ; 0 \leq \mathrm{q} \leq \mathrm{r})$

The self-sensitization in the photoelectrochemical activity of $\mathrm{AgCl}$ is due to silver clusters adsorbed on its surface. The silver cluster/silver chloride cluster phase boundary is of particular importance for understanding all the processes involved in the $\mathrm{AgCl} / \mathrm{Ag}^{+} / \mathrm{Ag}_{\mathrm{n}}$ electrode system. In the absence of an excess of $\mathrm{Ag}^{+}$and silver clusters, pure $\mathrm{AgCl}$ does not absorb light below the indirect bandgap transition, which is in the near UV at about $3.3 \mathrm{eV}$.

The photoreaction of $\mathrm{Ag}^{+} / \mathrm{AgCl} / \mathrm{Ag}_{\mathrm{n}}$ has recently been discussed by Tani [12] in detail from the view point of 


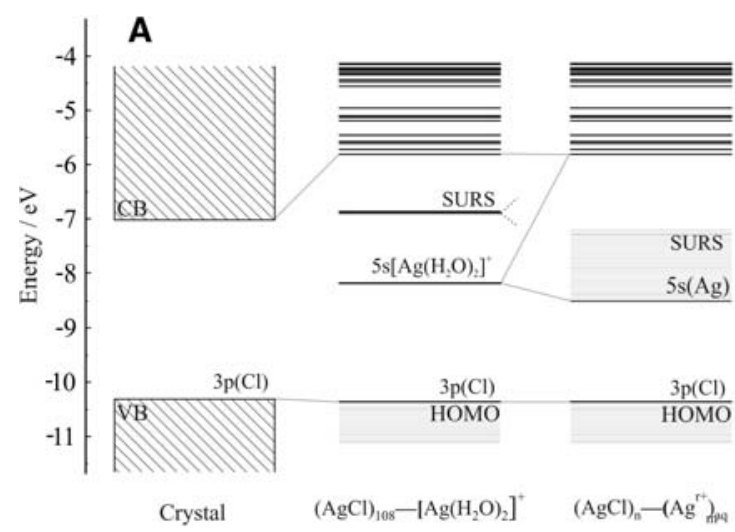

B

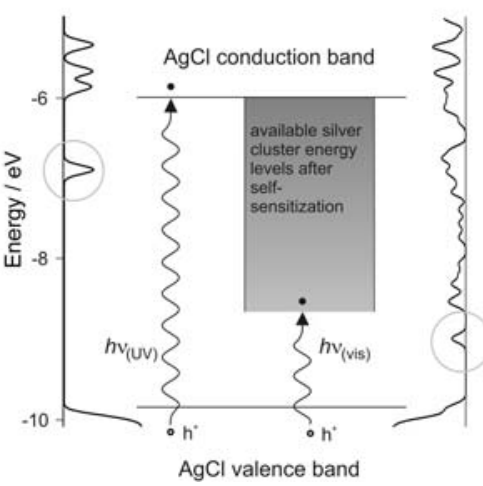

Fig. 11 Electronic structure of $\mathrm{AgCl}$ cluster modified with silver ions, hydrate silver ions and silvercluster on their surface. a Comparison of the electronic structure of an infinite $\mathrm{AgCl}$ crystal, a nano cluster with one $\left[\mathrm{Ag}\left(\mathrm{H}_{2} \mathrm{O}\right)_{2}\right]^{+}$adsorbed on its surface and one with several of them adsorbed, some of them already reduced and therefore represented as $\left(\mathrm{Ag}_{\mathrm{m}}^{\mathrm{r}+}\right)_{\text {aq }}$ with $\mathrm{r}$ smaller or equal to $\mathrm{m}$. The crystal band gap and $(\mathrm{AgCl})_{\mathrm{n}}-\left(\mathrm{Ag}_{\mathrm{m}}^{\mathrm{r}+}\right)_{\mathrm{aq}}$ values correspond to experimental values [77]. b Proposed mechanism of self-sensitization. The

solid state physics and photographic sensitivity. Quantum chemical calculations and comparison of experimental and calculated values for the ionization energy of differently sized silver clusters shows that Ag levels are located below the conduction band edge of $\mathrm{AgCl}$; Fig. 11. Additional $\mathrm{AgCl}$ surface states (SURS), as well as metal induced gap states (MIGS) from $\mathrm{Ag} / \mathrm{AgCl}$ cluster composites also present in the bandgap region of silver chloride. These different levels are responsible for the self-sensitization of silver chloride [77, 78]. They allow excitation of electrons, hence, creation of holes in the valence band by light absorption below bandgap energy. The energy of these transitions is lower than the energy needed for an optical transition from the $\mathrm{AgCl}$ valence band to its conduction band. Nevertheless, these new optical transitions in the visible spectral range can still initiate the oxidation of water since only the valence band is involved in the oxidation process. Thus, the photocatalytic oxidation of water on silver chloride is extended from the near UV into the visible range of the spectrum. This self-sensitization should not be confused with the spectral sensitization caused by silver clusters on silver chloride, also termed the photographic Becquerel effect. The latter observation has been attributed to electron injection from electron-donating silver clusters into the $\mathrm{AgCl}$ conduction band. Addition of small amounts of gold clusters has been shown to improve the performance of the $\mathrm{Ag}^{+} / \mathrm{AgCl} / \mathrm{Ag}_{\mathrm{n}}$ photoanodes [79]. Recently very interesting observations have been reported on silver exchanged titanosilicates which might become of importance for this research [80]. We also mention a plasmonic photocatalyst consisting of silver nanoparticles embedded in titanium dioxide [81]. It is not yet understood to what extent the plasmon resonance states of the silver- density of levels (DOL) of a $(\mathrm{AgCl})_{192}$ cluster is shown on the left and the local density of levels $(l-\mathrm{DOL})$ of the $\mathrm{Ag}_{115}-(\mathrm{AgCl})_{192}$ composite is shown on the right. We observe new induced levels below the LUMO of the $\mathrm{AgCl}$ cluster. A schematical view is shown in the middle. The lowest lying levels into which electrons can be excited are marked with a circle (left SURS, right MIGS). The position of the valence band is not markedly influenced by the $\mathrm{Ag}_{115}$ [78]

and gold clusters contribute to the behavior of the $\mathrm{Ag}^{+} / \mathrm{AgCl} / \mathrm{Ag}_{\mathrm{n}}$ system and it would be very interesting and important to know more about this.

One of the drawbacks of the $\mathrm{Ag}^{+} / \mathrm{AgCl} / \mathrm{Ag}_{\mathrm{n}}$ photoanode is the bad electron conductivity of silver chloride. Reversible systems could therefore only be realized for very thin layers. This causes insufficient light absorbtivity. We have shown that the system can be improved by using zeolite layers as a support which results in an increased surface area. The zeolite also acts as a reservoir for the needed $\mathrm{Ag}^{+}$ions which are electrochemicaly regenerated according to Eq. 7. It keeps them close to the photoactive layer so that they are not lost in the electrolyte. Preliminary result are encouraging despite of the fact that the zeolite crystals used were too large and the monolayers of the zeolite L crystals were of insufficient quality. Much improvement can be expected by using an arrangement as shown in Fig. 12, where the length of the well oriented zeolite L crystals is in the order of $100 \mathrm{~nm}$ or less. The layers must be prepared such that the channels are open in the direction of the photoactive surface and that they are well connected to the back electrode which consists of a thin gold layer e.g., coated on glass. Such experiments are now feasible because much progress has been made in the preparation of zeolite monolayers [6-8], [47], [50, 51], [82].

\section{Conclusions}

Zeolites and mesoporous silica are versatile host materials for the supramolecular organization of a large variety of guests. The inclusion of photoactive molecules, complexes, 


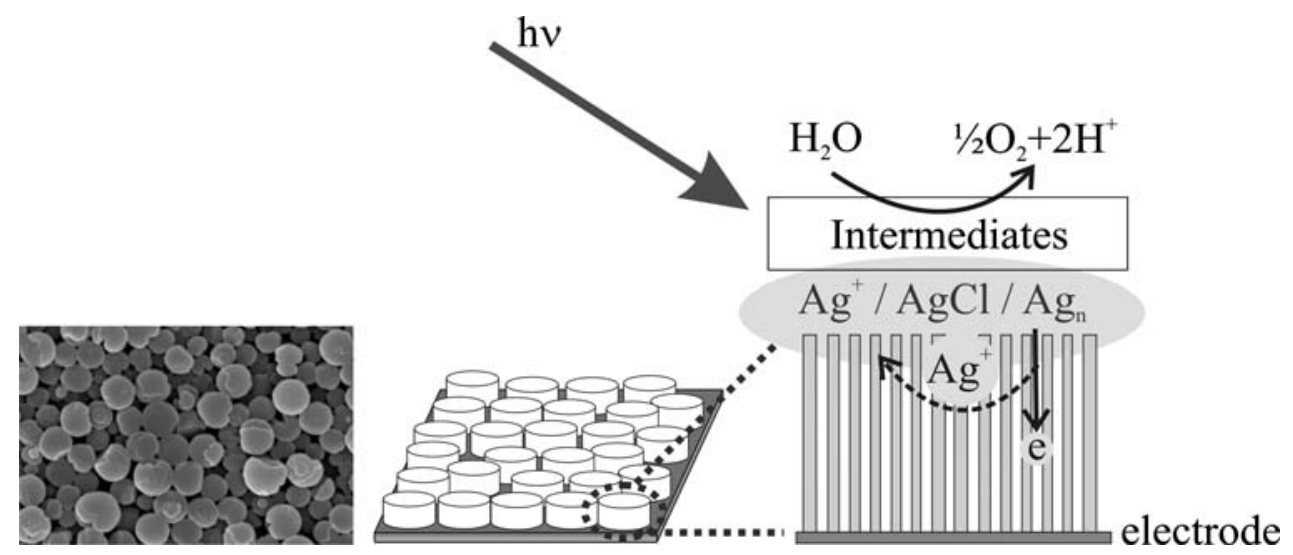

Fig. 12 Scheme of a $\mathrm{AgCl} / \mathrm{Ag}^{+} / \mathrm{Ag}_{\mathrm{n}}$-zeolite $\mathrm{L}$ based photoanode for photocatalytic water oxidation. Left monolayer consisting of less than $300 \mathrm{~nm}$ thick oriented zeolite L crystals with a diameter of about $600 \mathrm{~nm}$. Middle schematic view of a modified zeolite L monolayer. Right scheme of a single zeolite L crystal fixed on a gold electrode

or clusters into ordered 1-D channel systems is particularly intriguing, as the resulting host-guest compounds may exhibit properties such as optical anisotropy, efficient energy transfer, enhanced stability or specific photo activity. Several levels of organization have been realized for zeolite $\mathrm{L}$, extending from the interior of a given crystal to the channel entrances and the external surface as well as from the microscopic to the macroscopic scale. Diverse chemistry has been involved in the development of highly organized and functional host-guest materials, particularly also the design of molecules which are able to selectively adsorb at the channel entrances and establish communication between included guests and external objects. The new guest-zeolite $\mathrm{L}$ based building blocks are currently tested in devices. Their size, morphology, composition and optical properties need to be tailored to the specific task envisaged. The problems to be solved for realizing practical devices require efforts at the interface of chemistry, physics, and engineering. The zeolite based materials are more advanced, with respect to organizational level and with respect to realization of practical applications, than materials based on mesoporous hosts [4], [6]. The latter are, however, catching up [83, 84]. It has been discussed that despite the obvious differences between microporous and mesoporous host-guest materials, many similarities and analogies exist [6].

\section{References}

1. Balzani V, Credi A, Venturi M (2008) Chem Sus Chem 1:26-58

2. Benniston AC, Harriman A (2008) Mater Today 11:26-34

3. Calzaferri G, Huber S, Maas H, Minkowski C (2003) Angew Chem Int Ed 42:3732-3758

4. Calzaferri G, Lutkouskaya K (2008) Photochem Photobiol Sci 7:879-910 and modified with $\mathrm{Ag}^{+} / \mathrm{AgCl} / \mathrm{Ag}_{\mathrm{n}}$. The zeolite is fully exchanged with silver ions and may also contain some reduced silver particles. The processes taking place in the box "intermediates" are explained in Eqs. 6-12. Electron conductivity and photoactivity can be enhanced by adding small gold clusters

5. Johansson E, Choi E, Angelos S, Liong M, Zink JI (2008) J SolGel Sci Technol 46:313-322

6. Brühwiler D, Calzaferri G, Torres T, Ramm JH, Gartmann N, Dieu LQ, López-Duarte I, Martínez Díaz M (2009) J Mater Chem 19:8040-8067

7. Hashimoto S, Samata K, Shoji T, Taira N, Tomita T, Matsuo S (2009) Micropor Mesopor Mater 117:220-227

8. Lee JS, Ha K, Lee YJ, Yoon KB (2009) Top Catal 52:119-139

9. Armaroli N, Balzani V (2007) Angew Chem Int Ed 46:52-66

10. Bard AJ, Fox MA (1995) Acc Chem Res 28:141-145

11. Gust D, Moore TA, Moore AL (2001) Acc Chem Res 34:40-48

12. Tani T (2009) J Soc Photogr Sci Technol Japan 72:88-94

13. Osterloh FE (2008) Chem Mater 20:35-54

14. Currao A (2007) Chimia 61:815-819

15. Pullerits T, Sundström V (1996) Acc Chem Res 29:381-389

16. Förster Th (1948) Ann Phy (Leipzig) 2:55-75

17. Calzaferri G, Gfeller N (1992) J Phys Chem 96:3428-3435

18. Calzaferri G, Pauchard M, Maas H, Huber S, Khatyr A, Schaafsma T (2002) J Mater Chem 12:1-13

19. Ramamurthy V (1991) In: Ramamurthy V (ed) Photochemistry in organized and constrained media, chap 10 . VCH publishers, NY, pp 429-493

20. Turro NJ (2000) Acc Chem Res 33:637-646

21. Hashimoto S (2003) J Photochem Photobiol C: Photochem Rev 4:19-49

22. Abeykoon AMM, Castro-Colin M, Anokhina EV, Iliev MN, Donner W, Jacobson AJ, Moss SC (2008) Phys Rev B 77:1-10 075333

23. Hashimoto S, Yamaji M (2008) Phys Chem Chem Phys 10:31243130

24. Zhu J, Huang Y (2008) J Phys Chem C 112:14241-14246

25. Schulz-Ekloff G, Wöhrle D, van Duffel B, Schoonheydt RA (2002) Micropor Mesopor Mater 51:91-138

26. Corma A, Garcia H (2004) Eur J Inorg Chem 6:1143-1146

27. Tsotsalas M, Busby M, Gianolio E, Aime S, De Cola L (2008) Chem Mater 20:5888-5893

28. Kim HS, Pham TT, Yoon KB (2008) J Am Chem Soc 130:21342135

29. Bussemer B, Dreiling I, Grummt UW, Mohr GJ (2009) J Photochem Photobiol A Chem 204:90-96

30. Megelski S, Calzaferri G (2001) Adv Funct Mater 11:277-286

31. Zabala Ruiz A, Brühwiler D, Ban T, Calzaferri G (2005) Monatshefte für Chemie 136:77-89 
32. Zabala Ruiz A, Brühwiler D, Dieu LQ, Calzaferri G (2008). In: Schubert U, Hüsing N, Laine R (eds) Materials syntheses a practical guide, Springer, Wien, pp 9-19, ISBN 978-3-21175124-4

33. Ohsuna T, Slater B, Gao F, Yu J, Sakamoto Y, Zhu G, Terasaki O, Vaughan DEW, Qiu S, Catlow CRA (2004) Chem Eur J 10:5031-5040

34. Larlus O, Valtchev VP (2004) Chem Mater 16:3381-3389

35. Lee YJ, Lee JS, Yoon KB (2005) Micropor Mesopor Mater 80:237-246

36. Lee Y, Kao CC, Kim SJ, Lee HH, Lee DR, Shin TJ, Choi JY (2007) Chem Mater 19:6252-6257

37. Brent R, Anderson MW (2008) Angew Chem Int Ed 47:53275330

38. Breck DW (1974) Zeolite molecular sieves. Wiley, NY

39. Baerlocher Ch, Meier WM, Olson DH (2001) Atlas of zeolite framework types, 5th edn. Elsevier, Amsterdam

40. Pauchard M, Devaux A, Calzaferri G (2000) Chem Eur J 6:34563470

41. Calzaferri G (2008) Il Nuovo Cimento 123 B:1337-1367

42. Calzaferri G, Devaux A. In: Ramamurthy V, Inoue Y (eds) (2010) Supramolecular effects in photochemistry and photophysics. Wiley, New York (in press)

43. Davydov AS (1964) Usp Fiz Nauk 82:145-178

44. Busby M, Blum C, Tibben M, Fibikar S, Calzaferri G, Subramaniam V, De Cola L (2008) J Am Chem Soc 130:1097010976

45. Calzaferri G, patents EP1335879, US6932919, US7372012

46. Maas H, Calzaferri G (2002) Angew Chem Int Ed 41:2284-2288

47. Yoon KB (2007) Acc Chem Res 40:29-40

48. Huber S, Calzaferri G (2004) Angew Chem Int E 43:6738-6742

49. Busby M, Kerschbaumer H, Calzaferri G, De Cola L (2008) Adv Mater 20:1614-1618

50. Zabala Ruiz A, Li H, Calzaferri G (2006) Angew Chem Int E 45:5282-5287

51. Cucinotta F, Popovic ${ }^{\prime}$ Z, Weiss EA, Whitesides GM, De Cola L (2009) Adv Mater 21:1142-1145

52. Vohra V, Devaux A, Dieu LQ, Scavia G, Catellani M, Calzaferri G, Botta C (2009) Adv Mater 21:1146-1150

53. Suárez S, Devaux A, Bañuelos J, Bossart O, Kunzmann A, Calzaferri G (2007) Adv Func Mater 17:2298-2306

54. Koeppe R, Bossart O, Calzaferri G, Sariciftci NS (2007) Sol Energy Mater Sol Cells 91:986-995

55. Garwin RL (1960) Rev Sci Instr 31:1010-1011

56. Weber WH, Lambe J (1976) Appl Opt 15:2299-2300

57. Goetzberger A, Greubel W (1977) Appl Phys 14:123-139

58. Batchelder JS, Zewail AH, Cole T (1979) Appl Opt 18:30903110

59. Kittidachachan P, Danos L, Meyer TJJ, Alderman N, Markvart T (2007) Chimia 61:780-786

60. Brühwiler D, Dieu LQ, Calzaferri G (2007) Chimia 61:820-822
61. Currie MJ, Mapel JK, Heidel TD, Goffri S, Baldo MA (2008) Science 321:226-228

62. Calzaferri G, Li H, Brühwiler D (2008) Chem Eur J 14:7442_7449

63. Calzaferri G, Kunzmann A, Brühwiler D, Bauer Ch, Patent $\mathrm{CH}-698333$

64. Thomas JK (2005) Chem Rev 105:1683-1734

65. Laeri F, Schueth F, Simon U, Wark M (eds) (2003) Host-guest systems based on nanoporous crystals. $\mathrm{VCH}$, Weinheim, Germany

66. Calzaferri G, Leiggener C, Glaus S, Schürch D, Kuge K (2003) Chem Soc Rev 32:29-37

67. De Cremer G, Antoku Y, Roeffaers MBJ, Sliwa M, Van Noyen J, Smout S, Hofkens J, De Vos DE, Sels BF, Vosch T (2008) Angew Chem Int Ed 47:2813-2816

68. De Cremer G, Coutiño-Gonzalez E, Roeffaers MBJ, Moens B, Ollevier J, Van der Auweraer M, Schoonheydt R, Jacobs PA, De Schryver FC, Hofkens J, De Vos DE, Sels BF, Vosch T (2009) J Am Chem Soc 131:3049-3056

69. Kim SH, Thi TNN, Heo NH, Kim GH, Hong SB, Head JD, Seff K (2008) J Phys Chem C 112:11181-11193

70. Sendor D, Kynast U (2002) Adv Mater 14:1570-1574

71. Lezhnina M, Laeri F, Benmouhadi L, Kynast U (2006) Adv Mater 18:280-283

72. Wang Y, Li H, Gu L, Gan Q, Li Y, Calzaferri G (2009) Micropor Mesopor Mater 121:1-6

73. Schürch D, Currao A, Sarkar S, Hodes G, Calzaferri G (2002) J Phys Chem B 109:12764-12775

74. Currao A, Reddy VR, van Veen MK, Schropp REI, Calzaferri G (2004) Photochem Photobiol Sci 3:1017-1025

75. Reddy VR, Currao A, Calzaferri G (2007) J Mater Chem 17:3603-3609

76. Tani T (1995) Photographic sensitivity. Oxford University Press, NY

77. Glaus S, Calzaferri G (1999) J Phys Chem B 103:5622-5630

78. Glaus S, Calzaferri G, Hoffmann R (2002) Chem Eur J 8:17861794

79. Currao A, Reddy VR, Calzaferri G (2004) Chem Phys Chem 5:720-724

80. Agostini G, Usseglio S, Groppo E, Uddin MJ, Prestipino C, Bordiga S, Zecchina A, Solari PL, Lamberti C (2009) Chem Mater 21:1343-1353

81. Awazu K, Fujimaki M, Rockstuhl C, Tominaga J, Murakami H, Ohki Y, Yoshida N, Watanabe T (2008) J Am Chem Soc 130:1676-1680

82. Wang Y, Li H, Liu B, Gan Q, Dong Q, Calzaferri G, Sun Z (2008) J Solid State Chem 181:2469-2472

83. Inagaki S, Othani O, Goto $\mathrm{Y}$, Okamoto K, Ikai M, Yamanaka K, Tani T, Okada T (2009) Angew Chem Int Ed 48:4042-4046

84. Valtchev V, Mintova S, Tsapatsis M (2009) Ordered porous solids, resent advances and prospects, Elsevier, Amsterdam, ISBN 978-0-444-53189-6 